\title{
DESCRIPTION OF DEGRADATION INFLUENCE ON THE PLASTICIZED PVB DURING ITS RE-WORKING BY KNEADING
}

\author{
D. Měřínská, M. Tupý, J. Popelková, D.Pištěk, J. Zvoníček \\ Faculty of Technology, Tomas Bata University in Zlin
}

\section{ABSTRACT}

PVB sheet (type Butacite 3GO) with polymer chains containing butyraldehyde, hydroxyl- and small amount of acetate groups, was tested. These sheets were highly plasticized, with the content of plasticizer $28 \%$. Studied material was tested at different kneading conditions; especially the influence of temperature, oxygen, mechanical energy and created heat of dissipation was studied.

PVB sheet was kneaded at their usual humidity cca $0.5 \%$. Because PVB in known as the material with high hydroscopity, next tests were done on PVB sheets macerated in water. By this operation the humidity of sheets increases to the content $8.0 \%$. High humidity influenced all observed properties. Simultaneously, samples of PVB sheets re-worked by calendaring and pressing. At the calendaring the sheets were thermally stressed. The calendaring represents shear stress at low temperature. The degradation was evaluated as the change of optical properties, like the light transmittance through the re-worked material, created haze and yellowing. Next evaluated data were the change of mechanical properties - melt flow index and stress-strain behaviour. Summarized data were used for the choice of the optimal conditions for re-working of PVB sheets. The optimal conditions should bring the lowest energetic costs, minimal shear and thermo-oxidative degradation.

Keywords: $\quad$ Polyvinyl butyral, Degradation, Recycling, Kneading, Thermooxidation process

\section{INTRODUCTION}

Worldwidely, a lot of polymer waste is coming from the lamination and the production of PVB sheets. Unfortunately, the finding of optimal PVB waste re-working conditions is not easy [3]. Polyvinylbutyral is a material, which tends to the degradation, especially thermooxidative degradation of polymer chains at the shear stress. The following decrease of the molecular length brings the lowering of mechanical properties, elongation and viscosity in the melt. Worse mechanical properties of PVB sheet lower significantly its ability to absorb a mechanical energy created at the car crash $[1,3]$. In order to keep PVB properties after the re-working as higher as possible the optimal re-working conditions were studied, This means to find conditions, when after re-working the decrease of mechanical properties and yellowing are as low as possible. At the same time, the lowest energetic exigency of re-working process was evaluated. To minimize it the hydroscopity and the following rigidity drop was exploited [3]. However, the higher temperature can bring the hydrolyzation of butyral groups and consequently to change the final re-PVB properties.

Plasticized PVB sheet (Butacite type) with chains containing butyral and hydroxyl groups and small amount of acetate units was tested. The composition of the mentioned random copolymers was in the content cca 80, 18-19 and less than $2 \%$, partially $[1,2]$. Tested PVB sheet was highly plasticized with the content $28 \%$ of plasticizer triethylenglykol bis(2-ethylhexanoate)thereinafter named $3 G 0$.

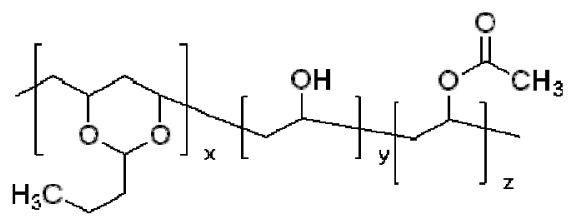

CP1042, IV th International Conference on Times of Polymers (TOP) and Composites edited by D. Acierno, A. D'Amore, and L. Grassia

(C) 2008 American Institute of Physics 978-0-7354-0570-7/08/ $\$ 23.00$ 
Fig. 1: Polyvinyl butyral chain structure

\section{PROCEDURES AND THEORY}

Studied plasticized PVB sheet was obtained from the company Retrim, the society re-working PVB waste for the commercial producer DuPont. PVB tested on thermodegradation (not chemically and mechanically), was prepared by pressing in the absence of the air. Samples were pressed between PET sheets, the press about $1 \mathrm{MPa}$ and temperatures 160,190 a $220^{\circ} \mathrm{C}$ during 10 minutes.

Next samples were kneaded in the kneader Brabender equipped with two blunders and the rapid ratio 2:3. The chamber had the volume $55 \mathrm{~cm}^{3}$ was heated. The PVB portion was $40 \mathrm{~g}$ and mixing time 10 minutes. The variables were temperature $\left(100,130,160,190\right.$ and $\left.220^{\circ} \mathrm{C}\right)$, and the rotational speed $\left(40,60\right.$ and $\left.80 \mathrm{~min}^{-1}\right)$. Used PVB samples had the water content $0,5 \%$, resp. 8,0\%). The higher water content was achieved by the soaking of PVB sheet in water for 14 days. These samples were named as "wet" PVB.

Due to the high viscosity of plasticized PVB at $70^{\circ} \mathrm{C}$ it was not possible to re-work these samples on the kneader. So, in this case, the samples were degraded by the shear stress on the laboratory calender with the different speed of rolls heated to $70^{\circ} \mathrm{C}$

Prepared re-worked material was pressed into the desks ( $1 \mathrm{~mm}$ thickness) at $130^{\circ} \mathrm{C}$. Consequently, bodies for mechanical property measurement were cut. Mechanical properties were measured on Alpha Technologies T 2000. The content of water was cca $0,6 \%$.

Melt flow index was evaluated by plastometer M 201 according to the ISO norm. Tempered samples were extruded through the capillary with $D=2 \mathrm{~mm}$. The relative humidity was $25 \%$, the power of pressing was $100 \mathrm{~N}$ at $423^{\circ} \mathrm{K}$

Carl Fischer method was used for the determination of water content. This method is based on the conductometry of water steam vaporized from the sheet into the special solution of iodide and sulphur dioxide in methanol.

\section{RESULTS AND DISCUSSION}

Mixing on the kneader was carried out at the $3 / 4$ filling of chamber which provided sufficient amount of oxygen for the possible thermooxidative degradation. Due to this degradation the lowering of PVB chains happened and it significantly influenced the mechanical properties of PVB sheet. With increasing temperature of re-working process it is possible to see clearly the decreasing of viscosity, shear strength and elongation (see Fig. 2.)

Samples re-worked by the pressing showed only minimal changes on MFI and mechanical properties. As a result of shear stress degradation the proportional increasing of elongation to the calendaring time was observed (till $250 \%$ after 14 minutes). 


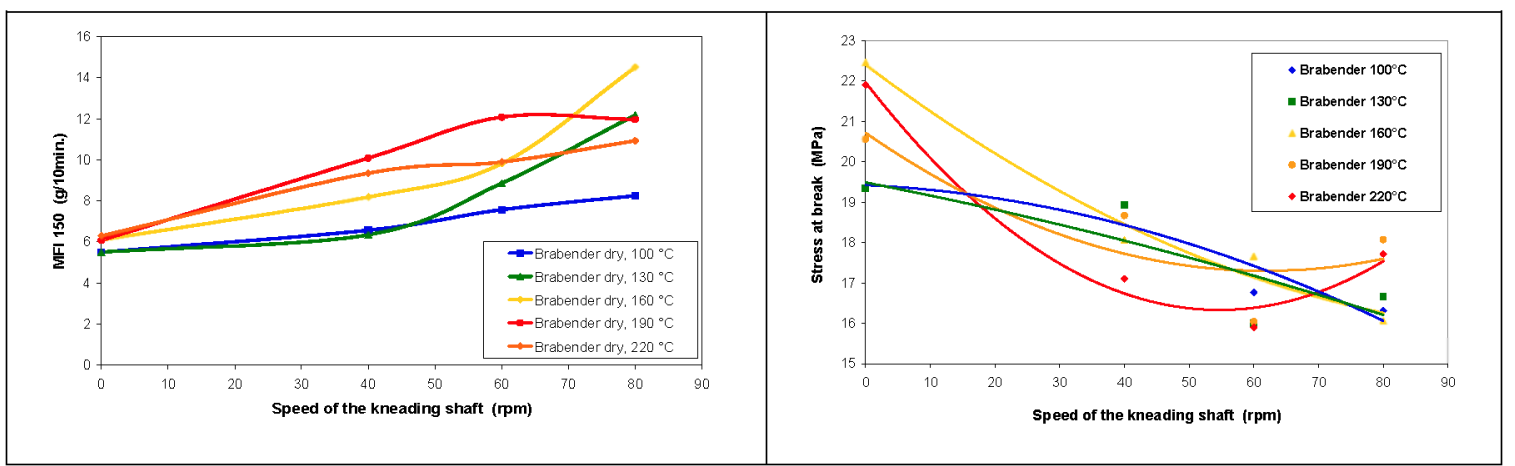

Fig 2: MFI and shear strength at kneading at different conditions

\section{Change of mechanical properties vs. water content}

PVB hodroscopity was used for the lowering of energetic exogency. Tested PVB sheet contained $8,0 \%$ of water. Water in the PVB matris acts as the next plasticizer lowwering the rigidity. The increasing of elongation and MFI was proportional to the water content. Contrary, shear strengh went down with the higherwater content. Although water vaporized quickly, its influence on the improvement of final mechanical properties was visible (see Fig 3). Arrows point to the values of origine PVB. Also the ideal re-working temperature $\left(150^{\circ} \mathrm{C}\right)$ with the lowest degradation is possible notice clearly. This result was also confirmed by the evaluation of yellwing and optical properties.

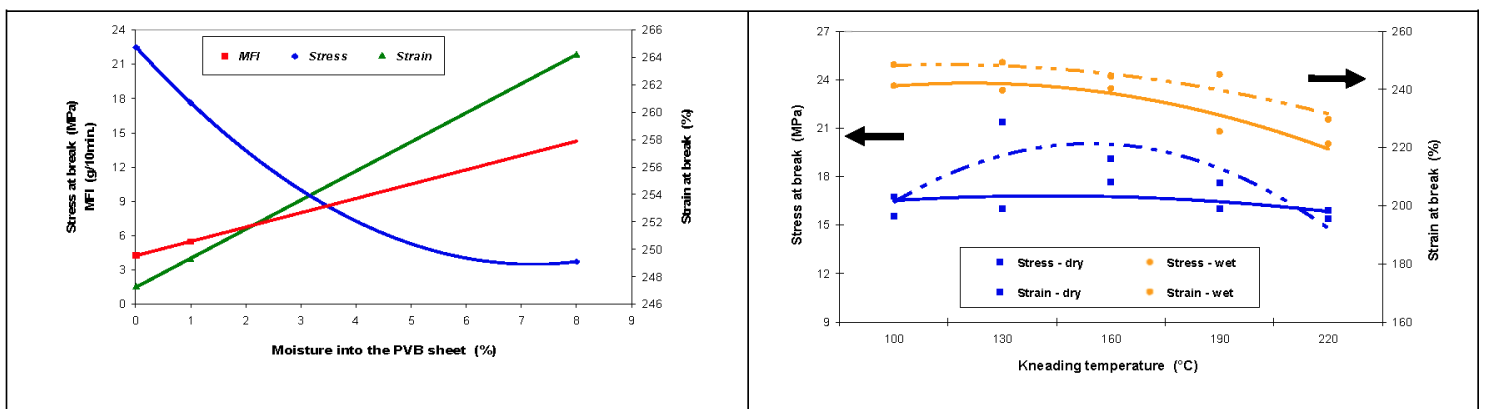

Fig. 3: Mechanical properties for "dry" and "wet" PVB samples kneaded at $60 \mathrm{~min}^{-1}$

\section{CONCLUSIONS}

The optimal PVB re-working conditions with the lowest degradation and energetic exigency were studied. The find conditions fulfilling these requests were about $150^{\circ} \mathrm{C}$ and rotational speed up to 50 $\mathrm{min}^{-1}$. Higher rotational speed caused lower degradation which was probably the consequence of a slip of blunders and by this a lower efficiency of a kneading process.

\section{REFERENCES}

1. M. Tupý, Re-working of PVB waste, Tomas Bata University, Faculty of technology, Plasty a kaučuk, 2008

2. A.K. Dhaliwal, J.N. Hay, The characterization of polyvinyl butyral by thermal analysis, Elsevier Thermochemica acta, 391 (2002), 245-255

3. J. Zvonicek, Collection of findings close to PVB extrusion process, Non-publish message, Zlin, 1998 
Copyright of AIP Conference Proceedings is the property of American Institute of Physics and its content may not be copied or emailed to multiple sites or posted to a listserv without the copyright holder's express written permission. However, users may print, download, or email articles for individual use. 